\title{
Repercussões da Gravidez em Adolescentes de 10 a 14 Anos em Contexto de Vulnerabilidade Social
}

\author{
Impact of Pregnancy on at-Risk, 10-14 Year-Old Adolescents
}

\author{
Rejane de Farias* \& Carmen Ojeda Ocampo Moré \\ Universidade Federal de Santa Catarina, Florianópolis, Brasil
}

\begin{abstract}
Resumo
Com o objetivo de identificar as repercussões ocorridas na vida de adolescentes que engravidaram entre 12 e 14 anos, em contexto de vulnerabilidade social, foram realizadas entrevistas semi-estruturadas e aplicados mapas de redes com 10 participantes, quando o filho estava entre um e três anos de idade. Os dados foram analisados qualitativamente, a partir da Teoria Fundamentada Empiricamente, de Anselm Strauss e Juliet Corbin. Os resultados evidenciaram que, após a experiência de gravidez e da maternidade, as adolescentes desenvolveram maior responsabilidade por sua vida reprodutiva e reformularam projetos, valorizando mais os estudos, apesar das dificuldades para retomá-los. O relacionamento com os parceiros caracterizou-se pela união estável, destacando-se a importância destes e das mães das adolescentes em seu processo de adaptação. Palavras-chave: Gravidez na adolescência, desenvolvimento, saúde sexual e reprodutiva, vulnerabilidade social.
\end{abstract}

\begin{abstract}
Aiming to identify the effects occurring in the lives of adolescents who became pregnant between 12 and 14 years old in a context of social vulnerability, we conducted semi-structured interviews and used network maps with 10 participants when their children were between 1 and 3 years old. The data were analyzed qualitatively, from the Empirically Grounded Theory of Anselm Strauss and Juliet Corbin. The results showed that after the experience of pregnancy and motherhood, adolescents developed greater responsibility for their reproductive lives and reviewed some future projects, giving more value to the studies, despite the difficulties to resume them. The relationship with partners was characterized by getting more stable, highlighting the importance of adolescents' partners and mothers in their adjustment process. Keywords: Adolescent pregnancy, development, sexual and reproductive health, social vulnerability.
\end{abstract}

A gravidez na adolescência é um fenômeno expressivo no Brasil, que envolve atualmente a faixa etária dos 10 aos 19 anos, de acordo com a Organização Mundial da Saúde (OMS), sendo a principal causa de internações dessas mulheres no Sistema Único de Saúde (SUS). No contexto da saúde pública, evidencia-se uma crescente preocupação com a faixa etária dos 10 aos 14 anos, pois além do registro do aumento de notificações, o último Censo Demográfico do ano 2000 registrou o nascimento de cerca de 40 mil crianças filhas de mulheres nesta faixa etária. Essa condição levanta indagações e desafios para diversos campos do conhecimento e das Políticas Públicas, uma vez que a gravidez entre adolescentes mostra-se um fenômeno complexo e que precisa ser pensado num contexto interacional, que envolve desde aspectos psicológicos do desenvolvimento da adolescente e sua família, até sua inserção na comunidade e interação com instituições e serviços (Instituto Brasileiro de Geografia e Estatística [IBGE], 2000; Ministério da Saúde, 2006; OMS, 1965).

\footnotetext{
${ }^{*}$ Endereço para correspondência: Labsfac-Departamento de Psicologia - CFH - UFSC, Campus Universitário, Trindade, Florianópolis, SC, Brasil. 88010-570. E-mail: labsfac@cfh.ufsc.br.
}

Do ponto de vista psicológico, a adolescência é um período do ciclo vital do indivíduo onde estão presentes conflitos em torno da definição de uma identidade sexual e ocupacional, caracterizando-se como o momento de integração do processo de constituição da personalidade. Tais transformações também produzem efeitos no ciclo vital da família, que necessita reorganizar sua dinâmica em busca de novos significados e papéis (Cerveny, 2002; Erikson, 1976). Os relacionamentos familiares costumam fazer parte da rede social significativa dos adolescentes, compreendida a partir de Sluzki (1997) como as relações que os mesmos percebem como significativas ou diferenciadas da massa anônima da sociedade, podendo incluir amigos, pessoas da vizinhança ou profissionais da saúde, educação e outras instituições (Sluzki, 1997).

A adolescência, no entanto, não pode ser caracterizada como um fenômeno universal, tendo em vista que a complexificação do processo educacional e consequente adiamento da entrada no mundo do trabalho, bem como o declínio de ideais ligados ao casamento e à família, são característicos da sociedade moderna ocidental. Neste contexto, adquire um lugar de prestígio, simbolizando um ideal cultural de liberdade e autonomia. Etapa importante no ciclo de vida individual e familiar, portanto, a adolescência atualmente vem sendo considerada uma idade 
propícia à escolarização, início da vida profissional e exercício da sexualidade desvinculado da reprodução (Coutinho, 2005; Taquette, 2008).

Neste contexto, a gravidez na adolescência, que no passado já contou com a aceitação da sociedade, vem sendo compreendida no presente como um processo que interrompe o crescimento e amadurecimento da adolescente, resultando em perdas de oportunidades. A literatura sobre essa temática é ampla, sendo que a maior parte dos estudos tem delineamento transversal e quantitativo, enfatizando aspectos negativos da vivência, enquanto os estudos qualitativos tendem a revelar aspectos positivos e adaptativos em relação à maternidade. Dentre alguns dos problemas comumente relacionados à esta condição, destacam-se os riscos para a saúde de mãe e filho, o baixo nível socioeconômico, o início precoce da menarca e relações sexuais, abandono escolar, violência sexual entre mulheres com menos de 14 anos, sofrimento psíquico e dificuldades na adoção de comportamentos contraceptivos, que se constituem como experiências subjetivas e graduais, adquiridas ao longo do tempo (Brandão \& Heilborn, 2006; Caputo \& Bordin, 2007; Cavasin et al., 2004; Cerqueira-Santos, Paludo, Schirò, \& Koller, 2010; Levandowski, Piccinini, \& Lopes, 2008; Sabroza, Leal, Souza, \& Gama, 2004; Taquette, 2008).

Além dos impactos em curto prazo, a gravidez na adolescência também tem sido associada a dificuldades que continuam a repercutir no desenvolvimento da adolescente e seu núcleo familiar, ao longo dos anos. Dentre as principais, podem-se citar os temores em serem desacreditas por pais e profissionais em sua capacidade de cuidar do filho, desemprego, ingresso precoce no mercado de trabalho não-qualificado, dificuldades para continuar os estudos, evasão escolar, sentimentos de perda, tristeza, solidão e isolamento, maus tratos infantis e separação conjugal. Sobre este último aspecto, Gradim, Ferreira e Moraes (2010) observaram que a gravidez é vivenciada de forma negativa na ausência do apoio do parceiro, sendo situação mais frequente entre as adolescentes menores de 16 anos. Nos casos onde a união se mantém, Heilborn et al. (2002) chamam a atenção ao movimento de internalidade por parte da mulher, que volta-se para o cuidado da casa e do filho, enquanto o marido busca o sustento externamente (Andrade, Ribeiro, \& Silva, 2006; Esteves \& Menandro, 2005).

Estudos realizados a partir dos depoimentos das adolescentes, no entanto, também revelam aspectos adaptativos, mostrando que as mães adolescentes sentem um grande amor pelos filhos e, a partir disso, são capazes de assumir a maternidade e a educação dos filhos para si, atendendo suas necessidades de cuidados diários e buscando ajuda de familiares e profissionais que possam lhes orientar e oferecer apoio. No que se refere às características maternas e cuidados com o recém nascido, Rugolo et al. (2004) não encontraram indicadores de problemas, mostrando que o desempenho das adolescentes assemelha-se ao de adultas nestas questões. Isto revela que uma perspectiva de ganhos e predomínio de sentimentos positivos também pode estar presente na vivência da maternidade adolescente, evidenciando múltiplas facetas em torno deste fenômeno, que pode resultar tanto em danos ao desenvolvimento da adolescente e seu filho, quanto em possibilidades organizadoras e significativas de vida (Andrade et al., 2006; Cerqueira-Santos et al., 2010; Dias \& Teixeira, 2010; Hoga, 2008).

Com relação ao desenvolvimento da adolescente, destaca-se que a gravidez provoca uma mudança de etapa no ciclo vital, fazendo com que a mesma comece a sentir-se parte do mundo adulto, mesmo quando reconhece sua falta de maturidade para lidar com as exigências desta nova etapa em sua vida. A adaptação satisfatória a este novo momento de vida, no entanto, costuma estar associada ao suporte da mãe e outros familiares, inclusive nos cuidados com o bebê, resultando num melhor enfrentamento das demandas decorrentes da maternidade, com a possibilidade de retomada dos estudos e estabelecimento do sentimento de satisfação por parte da adolescente em relação à maternidade (Andrade et al., 2006; Esteves \& Menandro, 2005; Falcão \& Salomão, 2006; Levandowski et al., 2008; López et al., 2005).

Esta dinâmica adquire características diferentes dependendo do contexto socioeconômico onde as adolescentes estão inseridas, tendo impacto significativo em seus projetos de vida. Entre mulheres de baixa renda que engravidaram na adolescência, os projetos de vida após a maternidade envolvem a busca de um emprego, o retorno às atividades escolares, o desejo por uma casa própria e o empenho para que o filho tenha uma vida melhor. Já as de classe média, buscam formação e profissionalização universitária, segurança de condições de desenvolvimento apropriadas aos filhos, além do desejo pela casa própria. Mas, apesar de algumas adolescentes relatarem a experiência da gravidez como gratificante e chegarem a se tornar boas mães, frequentemente projetos de vida como concluir os estudos, trabalhar e ser independente acabam sendo interrompidos, voltando-se para os papéis de mãe e dona-de-casa (Andrade et al., 2006; Esteves \& Menandro, 2005; Godinho, Schelp, Parada, \& Bertoncello, 2000; Hoga, 2008; López et al., 2005; Miño-Worobiej, 2008).

A consideração de aspectos como baixa escolarização, relações familiares violentas ou conflituosas, ausência ou insuficiência de recursos financeiros e serviços de saúde, além de poucas perspectivas profissionais e de futuro, constituem-se, portanto, enquanto fatores individuais, coletivos e contextuais que configuram o que se chama de vulnerabilidade social, uma vez que podem favorecer direta, ou indiretamente, a ocorrência da gravidez. Destaca-se, portanto, a necessidade de apreciar a complexidade em torno desta temática, uma vez que a experiência da gravidez é vivenciada de formas distintas, implicando também em diferentes possibilidades de redefinição das relações familiares e projetos de vida (Ayres, França, Calazans, \& Salleti Filho, 2003; Godinho et al., 2000; Hoga, Borges, \& Heberte, 2010). A 
partir disto, justifica-se a proposta deste estudo, que foi analisar as repercussões da gravidez na vida de adolescentes, cuja concepção deu-se entre 12 e 14 anos, em contexto de vulnerabilidade social, em nível subjetivo, comportamental, relacional, escolar e seus projetos de futuro.

\section{Método}

O presente estudo guiou-se pelos pressupostos da metodologia qualitativa, pois buscou os significados atribuídos às experiências e práticas cotidianas das adolescentes, caracterizando-se também por ser exploratório descritivo, na medida em que procurou descrever, caracterizar e relacionar aspectos das situações vividas pelas participantes (Flick, 2009).

\section{Participantes}

A pesquisadora chegou às participantes do presente estudo através do contato com equipes da Estratégia de Saúde da Família de dois municípios de uma região do Sul do Brasil. Após esclarecer os objetivos do estudo aos integrantes das equipes, os mesmos auxiliaram e intermediaram o contato com as adolescentes.

Cabe mencionar que o vínculo das participantes com as equipes mencionadas facilitou a aceitação da proposta, uma vez que as Agentes de Saúde exerceram uma função de mediação, agendando entrevistas e conduzindo pessoalmente a pesquisadora até a residência das participantes. Os critérios de inclusão na pesquisa foram: (a) idade da adolescente entre 12 e 14 anos na época da gravidez e (b) primeiro filho com idade entre 1 e 3 anos, no momento da entrevista.

Dessa forma, foram contatadas dez adolescentes que, após esclarecimentos e consentimento por escrito dos responsáveis, concordaram em participar da pesquisa. Destas, sete pertenciam ao município de menor porte, com população de aproximadamente 56.000 habitantes. As outras três pertenciam às regiões de abrangência de uma equipe de saúde do município de maior porte, com população estimada de 202.000 habitantes. Segundo as equipes de saúde, as regiões caracterizam-se pela presença de famílias de baixa renda, violência, tráfico de drogas, crescimento desordenado e saneamento básico precário.

\section{Instrumentos}

A coleta de dados foi realizada com o auxílio de dois instrumentos: uma entrevista semi-estruturada e o Mapa de Redes (Sluzki, 1997). O primeiro instrumento foi composto por dados sócio-demográficos de identificação, e questões norteadoras referentes à: (a) experiência da adolescente desde o momento anterior à gravidez, incluindo o relacionamento com o parceiro, a família e os estudos, (b) reações à notícia da gravidez, (c) vivência da gestação, parto e puerpério, (d) mudanças subjetivas, (e) projetos de vida e (f) rede social significativa. O segundo instrumento foi o Mapa de Redes, proposto por Sluzki
(1997), que se constitui num diagrama, composto por quatro quadrantes: família, amizades, trabalho/estudos e comunidade, subdivididos em três círculos (interno, médio e externo), os quais evidenciam o grau de proximidade e significação das pessoas da rede em torno da participante entrevistada. Este instrumento foi complementar à entrevista semi-estruturada e possibilitou identificar e registrar a rede social significativa das participantes, em três momentos diferentes de suas vidas - antes da gravidez, durante a gestação e no momento da entrevista.

Todos os dados foram gravados, após autorização, com a finalidade de preservar com exatidão a fala das entrevistadas e possibilitou, posteriormente, a transcrição fiel das narrativas.

\section{Procedimentos}

As entrevistas foram realizadas na residência das adolescentes ou na Unidade de Saúde, mas sem a presença de agentes comunitárias, respeitando-se a individualidade e a privacidade das entrevistadas. Antes de iniciar a entrevista, a pesquisadora voltava a esclarecer os objetivos do estudo, verificando o interesse da adolescente e a assinatura do Termo de Consentimento Livre e Esclarecido. Também era solicitada autorização verbal para o uso do gravador, sendo assegurado à adolescente o sigilo de sua identidade. A coleta de dados começava com o preenchimento dos dados de identificação, seguida da entrevista semi-estruturada e confecção do mapa de redes. Após o término, a pesquisadora deixava um telefone de contato, colocando-se à disposição da adolescente caso ela desejasse comunicar-se com a mesma.

\section{Análise dos Dados}

Para a organização e análise dos dados foi utilizada a "Grounded Theory" (Teoria Fundamentada Empiricamente), proposta por Strauss e Corbin (2008), a qual permite agrupar, comparar e relacionar de modo sistemático os dados em torno do objetivo do estudo. Seguindo os passos dos autores acima mencionados o processo de análise envolveu as seguintes etapas: (a) interação com os dados, através de leituras sucessivas do material textual das entrevistas, o qual permitiu uma análise em profundidade dos dados e possibilitou a ampliação da compreensão do significado das experiências descritas pelas participantes, sendo esta etapa denominada de codificação aberta; (b) então, os dados foram desmembrados, examinados e comparados, possibilitando a elaboração de categorias de acordo com suas especificidades; (c) as categorias foram nomeadas a partir da emergência de pontos nucleares, que foram se mantendo na diversidade e particularidade dos dados, buscando chegar à representação e integração dos significados dos códigos agrupados. Esta etapa é denominada de axial; (d) a partir das categorias principais, relacionaram-se as respectivas subcategorias de análise, as quais auxiliaram na descrição, compreensão e sustentação em profundidade das categorias principais, sendo isto denominado pelos autores mencionados, de etapa 
Farias, R. \& Moré, C. O. O. (2012). Repercussões da Gravidez em Adolescentes de 10 a 14 Anos em Contexto de Vulnerabilidade Social.

seletiva. Assim, delinearam-se um conjunto de seis categorias, com suas respectivas subcategorias de análises que, tomados em seu conjunto, apoiaram uma compreensão integrada do objetivo deste artigo.

\begin{tabular}{|ll|}
\hline 1. Relacionamento com o filho & 1.1. Significados do filho e da maternidade \\
& 1.2. Relação com a criança \\
& 1.3. Relação da criança com outras pessoas \\
& 2.1. Satisfação com o marido enquanto pai \\
& 2.2. Satisfação na relação com o marido/companheiro \\
& 2.3. Mudaças na relação do casal \\
3. Modificações dos relacionamentos familiares & 3.1. Aproximação e satisfação na relação com os familiares \\
& 3.2. Sentimento de que a relação não mudou \\
& 3.3. Vivências de afastamento ou luto por familiares \\
4. Mudanças subjetivas e comportamentais & 4.1. Melhoria do conhecimento e uso de contraceptivos \\
& 4.2. Ganhos e satisfações a partir da maternidade \\
& 4.3. Dificuldades ou sentimentos de arrependimento \\
& 4.4. Modificações nos relacionamentos \\
4.5. Cotidiano e as condições de vida & 5.1. Dificuldades e interrupções dos estudos \\
5. Trajetória escolar & 5.2. Processo de retomada dos estudos \\
& 5.3. Postura atual em relação aos estudos \\
6. Planos para o futuro & 6.1. Planos envolvendo a vida familiar \\
& 6.3. Dificuldades ou ausência de planos
\end{tabular}

Figura 1. Sistema de categorias e subcategorias de análise.

Cabe destacar que a partir da sexta entrevista observaram-se regularidades nas informações e reincidência temática, referentes ao objetivo do presente estudo. Esta reincidência temática evidenciou o que Strauss e Corbin (2008) denominam de ponto de saturação dos dados, e que foi confirmado pelos dados das entrevistas subsequentes, na medida em que gravitaram em torno das reincidências que já haviam se configurado.

Cumpre informar que a pesquisa foi aprovada pelo Comitê de Ética de Pesquisa com Seres Humanos da Universidade Federal de Santa Catarina (UFSC), sob o protocolo 10/2009, e contou com a autorização dos responsáveis pelas adolescentes, através do Termo de Consentimento Livre e Esclarecido.

\section{Resultados e Discussão}

Tendo como referência epistemológica o reconhecimento da complexidade da temática estudada (Morin, 2005), apresenta-se, em continuação, a caracterização das participantes. A idade das adolescentes, no momento do estudo, variou entre 15 e 18 anos, sendo que a média foi de 17 anos e todas viviam em união estável com os pais de seus filhos. As dez participantes também possuíam conhecimentos sobre métodos contraceptivos antes de engravidar, sendo que cinco adolescentes planejaram conscientemente a gravidez.
A maior parte dos casais teve apenas um filho (sete deles), dois casais tiveram duas crianças e um aguardava o nascimento do segundo filho, no momento da entrevista. A idade do primeiro filho, que variou de um a três anos, apresentou uma média de dois anos e meio por criança. $\mathrm{O}$ nascimento destes deu-se através de parto normal, para sete adolescentes, e parto cesariana para as outras três.

Sobre as condições de habitação, seis adolescentes moravam em residência própria, duas em residências alugadas e uma residia com a sogra, mas já estava construindo uma casa no terreno da mãe. As moradias, em geral, eram feitas de madeira e contavam com um ou dois cômodos, sendo que as crianças dormiam junto com os pais. Algumas adolescentes manifestaram abertamente seu descontentamento com o espaço, classificado como pequeno, ou "caindo aos pedaços".

O marido destacou-se como o principal provedor financeiro da família, sendo que os casais viviam com uma renda familiar média de R $\$ 1.200,00$. Quatro adolescentes contribuíam para o rendimento, trabalhando como auxiliar de serviços gerais, balconista, auxiliar de produção e funcionária de uma fábrica. As demais dedicavam-se a cuidar dos filhos. Quatro adolescentes estavam estudando no momento da entrevista, sendo que duas destas, também trabalhavam. As demais não estavam estudando, apesar de algumas fazerem planos para retomar os estudos. 
No que diz respeito à primeira categoria de análises denominada de relacionamento com o filho (1) foram abordados os sentimentos e acontecimentos, envolvendo a relação das adolescentes com os filhos. Nesse sentido, quando indagadas sobre o significado do filho e da maternidade (1.1), as dez adolescentes afirmaram que ele(a) era a coisa mais importante na vida delas, apresentando unanimidade nas respostas, sendo que os termos mais utilizados foram as palavras "tudo", "vida" e "o mais importante". Por sua vez, ao falar sobre os significados da maternidade, realizaram auto-avaliações positivas, evidenciando expectativas de se dedicar e preocupações, tanto com a saúde da criança quanto com a transmissão de ensinamentos.

Os dados evidenciaram que as adolescentes sentiamse, de certo modo, satisfeitas com o seu desempenho enquanto mães e ao mesmo tempo apresentavam forte exigência consigo mesmas, esta última manifesta pela visão de que a maternidade e os cuidados com a criança deveriam ser exercidos sem o auxílio de outras pessoas. Destacou-se o envolvimento das mesmas com a função materna, tendo assumido a posição de principal cuidadora da criança. Neste sentido, as falas levantaram a reflexão de que as principais dificuldades encontradas pelas adolescentes não relacionaram-se com a capacidade para cuidar e atender às necessidades da criança em si, como também encontrou Rugolo et al. (2004), mas à autonomia financeira, dificultada pela incompletude dos estudos, dentro do que já havia apontado Andrade et al. (2006).

Na subcategoria relação com a criança (1.2) os discursos enfatizaram tanto dificuldades, sentimentos de impaciência e ambivalência em relação ao filho, como satisfação com o relacionamento e tarefa de cuidar dos filhos, numa perspectiva onde predominaram sentimentos de ganhos com a maternidade, conforme sinalizado por Hoga (2008). Por fim, ao falar sobre a relação da criança com outras pessoas (1.3) algumas adolescentes expressaram sentimentos de gratidão pela ajuda que a escola ou familiares vinham prestando na educação da criança e sentimentos de ciúme pelo apego do fillho com os avós.

Os relatos dessa categoria, ordenados através das subcategorias, indicaram que as adolescentes tomaram os cuidados de seus filhos para si (Cerqueira-Santos et al., 2010), vivenciando dificuldades, desafios e satisfações no exercício da maternidade, o que sugere que a imprevisibilidade e multiplicidade de implicações possíveis a partir da gravidez foi o que, de fato, pode-se constatar como característico neste período.

A segunda categoria relacionamento com o marido (2) abordou sentimentos, acontecimentos e modificações identificadas pela adolescente no relacionamento com o marido, após o nascimento do filho. A satisfação com o marido enquanto pai (2.1) foi citada por seis adolescentes, que demonstraram reconhecimento e admiração pelo relacionamento entre o marido e o filho, eviden- ciando também a participação deste nos cuidados e educação das crianças. A satisfação na relação com o marido/companheiro (2.2) também foi mencionada por cinco adolescentes, que ressaltaram qualidades consideradas papéis tradicionalmente masculinos como o de "provedor" e "protetor", o que pareceu ter sido importante para a integração e a constituição da nova família, contribuindo na adaptação da adolescente à maternidade, conforme sinalizaram Gradim et al. (2010).

As adolescentes também mencionaram mudanças na relação do casal (2.3) após o nascimento do filho, sendo que das dez entrevistadas, cinco referiram-se que o relacionamento melhorou, quatro consideraram que houve piora e uma citou a experiência de separação e reconciliação. A partir dos relatos foi possível vislumbrar que o sentimento de melhoria no relacionamento do casal esteve relacionado, para algumas adolescentes, a um processo de amadurecimento dela ou do companheiro, manifestado pelo comportamento de voltar-se para a família, "passar mais tempo em casa", "pensar no que vai falar", "e não falar besteiras".

As adolescentes, que mencionaram pioras no relacionamento do casal, destacaram aspectos variados. Para uma delas, o desejo de retornar à escola produziu conflitos com o marido, sendo que esta insistência em retomar projetos de vida já foi apontada por Miño-Worobiej (2008) entre adolescentes escolarizadas. Para outra, o relacionamento do casal sofreu um impacto negativo em função da precariedade da habitação e da falta de condições financeiras. Também foram mencionados sentimentos de ciúmes em relação à atenção destinada pelo marido aos filhos e de desvalorização do lugar feminino após o casamento, o que pode relacionar-se com as restrições femininas no movimento de internalidade, descritas por Heilborn et al. (2002).

$\mathrm{O}$ conjunto de dados a respeito do relacionamento das adolescentes, com os pais de seus bebês desde o início do namoro até o momento atual, revelou que estas relações, ainda que permeadas por idealizações, conflitos ou dificuldades, constituíram-se como uniões afetivas com certa estabilidade, que giravam em torno da ideia de ter uma família e um espaço diferenciado da família de origem, o que também pode representar a possibilidade de reincidência de gravidez, de acordo com Souza-Mata, AraújoLemos, Lira-Ferreira, Pereira-Braga e Chaves-Maia (2009). Estes achados divergiram tanto do que foi encontrado por Cavasin et al. (2004) sobre a gravidez enquanto fruto de violência sexual, quanto por Godinho et al. (2000), que observaram uma relação direta entre a idade da adolescente e a instabilidade da relação, o que pode ter ocorrido em função das adolescentes contarem com o suporte de suas mães, companheiros e outras pessoas significativas, evidenciando o que apontaram Dias e Teixeira (2010), de que a gravidez pode ter consequências tanto negativas quanto positivas.

A terceira categoria modificações dos relacionamentos familiares (3) tratou dos sentimentos, acontecimentos e 
modificações identificados pela adolescente no relacionamento com os familiares, após o nascimento do filho. Sete adolescentes fizeram referências de aproximação $e$ satisfação na relação com os familiares (3.1), relatando suas impressões de que o relacionamento ficou melhor em função de seu próprio amadurecimento, ou a partir da superação do conflito que se estabeleceu quando a gravidez foi descoberta. Para outras, a melhoria relacionou-se à chegada do filho, numa referência aos vínculos dos familiares com a criança. Assim, percebeu-se, de um modo geral, movimentos de redefinições das relações familiares (Hoga et al., 2010) com acolhimento das adolescentes, especialmente por parte de sua mãe, como apontaram Falcão e Salomão (2006), evidenciando um apaziguamento dos conflitos, com maior proximidade e solidariedade entre os membros da família, após o convívio da criança com a família ampliada.

O sentimento de que a relação não mudou (3.2) também foi mencionado por quatro adolescentes, enfatizando que o relacionamento com a família não mudou porque já era bom. Já as vivências de afastamento ou luto por familiares (3.3) envolveram os conflitos de uma adolescente com seu pai e morte de pessoas da família, em outros casos. Na primeira situação, constatou-se que a relação da adolescente com o pai já era permeada de conflitos antes mesmo da gravidez e, após um período de apaziguamento, retornou ao antigo padrão. Essa observação provocou uma reflexão sobre até que ponto a gravidez da adolescente é capaz de "solucionar" conflitos familiares e promover uma aproximação duradoura entre os membros da família. Já o luto, esteve associado a movimentos de reorganização da rede de relacionamentos das adolescentes, com o surgimento de figuras substitutas.

A análise desta categoria sobre as dificuldades e ausências de diálogo com a família, antes da gravidez, revelaram um contraste em relação ao momento da entrevista, quando o relacionamento mostrou-se predominantemente satisfatório e com maior presença de diálogo e solidariedade entre seus membros. Assim, percebeu-se que houve uma transição da família para uma nova fase do ciclo vital, conforme descrita por Cerveny (2002), onde o nascimento de um novo membro produziu um período de crise, acompanhado de uma reorganização do sistema familiar, que culminou com a mudança na função que os membros exerciam na família, revelando que, de certa maneira, as famílias reorganizaram-se de modo suficientemente satisfatório na tarefa de acolher a criança (Hoga et al., 2010) .

$\mathrm{Na}$ quarta categoria mudanças subjetivas e comportamentais (4) foram abordadas as mudanças identificadas pela adolescente em si mesma, ou em sua vida após a experiência de tornar-se mãe. A melhoria do conhecimento e uso de contraceptivos (4.1) foram mencionados por todas as adolescentes, confirmando as observações de Brandão e Heilborn (2006) sobre o controle da contracepção enquanto experiência subjetiva que se adquire com o passar do tempo, uma vez que constatou-se uma transformação da postura da adolescente frente à sua vida reprodutiva no sentido de responsabilizar-se ativamente pela contracepção.

Nove adolescentes também falaram sobre ganhos $e$ satisfações a partir da maternidade (4.2), sendo que sete delas ressaltaram que amadureceram ou ficaram mais calmas após a maternidade, sinalizando que as adolescentes adquiriram maior consciência sobre as consequências de seus atos, de modo que passaram a refletir sobre suas ações e preocupar-se mais com os relacionamentos, cuidados com a criança e futuro da família. A dedicação ao filho também foi citada por seis entrevistadas, que enfatizaram o quanto hoje pensam primeiro nos filhos, deixando em evidência o sentimento de responsabilidade que se desenvolveu nelas a partir da gravidez. Apesar das preocupações, seis adolescentes afirmaram que não se arrependeram de ter engravidado, manifestando também que a vida mudou para melhor.

As dificuldades ou sentimentos de arrependimento (4.3), também estiveram presentes, envolvendo, para três adolescentes, sentimentos de tristeza e dores que, quando tomadas em conjunto com a história de vida destas entrevistadas, pareceram expressar problemas com os quais as adolescentes foram se deparando e que se constituíram em uma "carga extra", difícil de lidar, como a insatisfação conjugal, uma nova gravidez ou problemas de saúde do filho. Outra dificuldade, citada com frequência, referiu-se à diminuição das saídas para se divertir, indo ao encontro dos achados de Esteves e Menandro (2005) e Velho (2003). Identificou-se que as saídas não concretizadas do casal pareceram mais associadas às dificuldades das adolescentes para separarem-se dos filhos, ou cansaço em função do dia a dia que, para algumas inclui trabalho o dia inteiro, estudo no período noturno, cuidados com a casa e com a criança.

A fala de uma das adolescentes, contando que aos dez anos já saía e que aos 14 anos já havia cansado de tanto aproveitar, também pode estar sinalizando um paradoxo, onde a busca da condição de prestígio e liberdade da adolescente convive com o rompimento de um pensamento hegemônico de que nesta idade o exercício da sexualidade esteja voltado, exclusivamente, ao prazer e não à reprodução e constituição de família (Coutinho, 2005; Taquette, 2008).

Sentimentos de arrependimento por ter engravidado estiveram presentes em três adolescentes, que apresentaram como característica em comum o uso de contraceptivos, visando evitar a gravidez. Isso levantou reflexões sobre o trabalho dos profissionais da saúde com adolescentes, uma vez que os dados sugerem que adolescentes que não desejam a gravidez podem estar mais receptivas às orientações e ações preventivas em relação à gravidez, mas necessitam de maior apoio e acolhimento quando a gravidez acontece. Já as adolescentes que buscam ativamente a gravidez lançam maiores desafios na realização de um trabalho que possa ajudá-las a refletir sobre seus desejos e os desafios decorrentes de sua 
efetivação, de forma a contribuir no processo de responsabilização por suas escolhas. No entanto, parecem adaptar-se com mais facilidade à maternidade quando esta acontece, manifestando maior satisfação e disponibilidade para a função materna.

A necessidade de que não só a família, mas também os profissionais que trabalham com adolescentes, auxiliemnas na construção de projetos de vida que adiem a maternidade, ficou ainda mais evidente com a fala de sete entrevistadas, contando-se que, mesmo que não tenham se arrependido e ainda que experimentem satisfação com a maternidade, se pudessem voltar no tempo teriam adiado a gravidez para um momento com melhores condições de vida (estudo, trabalho e moradia), de forma a vivenciar a maternidade sem passar por tantas dificuldades, especialmente de ordem financeira. As entrevistadas também perceberam que poderiam ter "aproveitado" mais a adolescência, tanto no sentido de se divertir, quanto de investir em projetos profissionais.

As transformações relatadas pelas adolescentes em suas vidas incluíram também modificações nos relacionamentos (4.4), evidenciadas pelo impacto da maternidade nas relações de amizade e diante de estranhos. Os relatos sobre as amizades mostraram que, após a maternidade, as adolescentes começaram a sentir-se parte do mundo adulto, como apontado por López et al. (2005) e passaram a identificar-se com "gente mais madura", não compartilhando mais dos mesmos assuntos com as amigas da mesma idade. Já a reação de "estranhos" frente à maternidade das adolescentes gerou, em alguns casos, constrangimentos evidenciados por atitudes como "aumentar" a idade, e também produziram ansiedades a respeito da capacidade da adolescente de cuidar de seu filho, indo ao encontro do que apontaram Andrade et al. (2006).

A transição para a nova condição também foi observada através de falas que mostraram o esforço da adolescente para adaptar-se ao papel de mãe, mulher casada e independente da família de origem. Estes dados, pensados em conjunto com os demais relacionamentos das adolescentes, sinalizaram o quanto a transição do papel de filha para o de mãe implicou numa reformulação de todos os relacionamentos das adolescentes, desde as pessoas mais próximas, como os membros da família, até as amizades e pessoas estranhas.

Ao falar sobre as mudanças geradas a partir da gravidez, as adolescentes também mencionaram o cotidiano e as condições de vida (4.5), onde foram citados os esforços para fugir da violência e das condições precárias de habitação, as mudanças na rotina e a relação da adolescente com o trabalho. O depoimento sobre a vida no morro, com as dificuldades de saneamento básico e a violência constante e tolhimento da liberdade pelas "leis" do tráfico, evidenciam aspectos do ambiente, associados ao contexto de vulnerabilidade social. A vivência da maternidade parece ter intensificado ainda mais o desejo da adolescente de residir em outro local, transformando-se num projeto de vida.
As adolescentes também falaram sobre a mudança de suas rotinas, que hoje estão organizadas em função dos filhos e do trabalho, sendo este último visto apenas como fonte de renda para algumas, enquanto para outras representava possibilidades de satisfação, associando-se a planos para melhorar sua condição de vida. A experiência da gravidez e a maternidade, portanto, desencadearam uma série de modificações subjetivas e comportamentais nas adolescentes, que perceberam amadurecimento e aumento na responsabilização em relação às suas vidas $\mathrm{e}$ contracepção, com a presença tanto de sentimentos positivos e de satisfação em relação à maternidade quanto de arrependimento, incluindo dificuldades e modificações no seu cotidiano e relacionamentos.

$\mathrm{Na}$ quinta categoria denominada de trajetória escolar (5) foram abordadas as modificações ocorridas na maneira da adolescente compreender e se posicionar em relação à escola e seus estudos, bem como acontecimentos, sentimentos e interferências que ocorreram em sua trajetória escolar a partir da gravidez. Das dez adolescentes, no momento da entrevista, apenas quatro estavam estudando, duas cursando o supletivo e outras duas o ensino regular. Três adolescentes planejavam retomar os estudos e outras três disseram que até gostariam, mas consideravam difícil que isto ocorresse. Sete adolescentes falaram sobre as dificuldades e a interrupções dos estudos (5.1), expressando as dificuldades em conciliálos com a maternidade, seja em função dos cuidados com o filho ou pelo contexto violento que dificulta o deslocamento no período noturno. Percebeu-se, ainda, que as adolescentes gostariam mas não viam perspectivas de retorno à escola, em função dos cuidados com os filhos, a presença de sentimentos de perda e tristeza, conforme encontrou Velho (2003).

O processo de retomada dos estudos (5.2) também foi abordado por adolescentes que voltaram a estudar e contaram com apoio ou resistências para concretizar seu retorno. O papel do suporte dos familiares, na retomada dos projetos das adolescentes, voltou a evidenciar-se, ressaltando a importância do que apontou Sluzki (1997) sobre as redes sociais significativas. A mãe, o marido e a sogra foram citados como as pessoas que cuidavam das crianças no período em que as mesmas estavam na escola e constitui-se como um elemento fundamental para o processo de continuidade dos estudos, por parte das adolescentes.

Por fim, oito adolescentes falaram sobre sua postura atual em relação aos estudos (5.3), abordando a consciência sobre a importância da escolaridade e seus planos de continuidade. $\mathrm{O}$ valor dos estudos, evidenciado tanto por sua importância no mercado de trabalho, quanto pelo desejo de continuidade, no entanto, só foi percebido pelas adolescentes após a experiência de gravidez e maternidade, ressaltando uma mudança na postura das entrevistas a esse respeito. Corroborou-se os achados de Dias e Teixeira (2010) e Heilborn et al. (2002) sobre a maior frequência de evasão escolar nas classes populares, tanto 
antes quanto após a gravidez, quando a inserção da mulher no mercado se faz imperiosa. Entre as entrevistadas, percebeu-se que o retorno aos estudos esteve diretamente atrelado à existência de uma rede de suporte, que garantisse os cuidados com a criança nos períodos de ausência materna, de modo que o suporte social e o financeiro foram evidenciados como os principais fatores associados à continuidade da vida escolar da adolescente.

$\mathrm{Na}$ sexta categoria denominada planos para o futuro (6) foram relatados os planos estabelecidos pela adolescente, ou pelo casal para o futuro após a experiência da maternidade. No que se refere aos planos envolvendo a vida familiar (6.1), sete adolescentes falaram sobre o desejo de evitar ou adiar uma nova gravidez em função de preocupações com as questões financeiras e do contexto social que, no seu ponto de vista, não favorecia o cuidado de crianças. Outras citaram o desejo de construir a casa própria, criar os filhos e conciliar trabalho com estudos. As narrativas mostraram que a maternidade implicou numa reformulação dos planos das adolescentes, que se tornaram mais objetivos e voltados para a melhoria das condições de vida da família, confirmando as observações de Hoga (2008) de que a incorporação do papel de mãe à identidade das jovens foi um estímulo na busca por uma melhor qualidade de vida.

Sete adolescentes enfatizaram planos envolvendo trabalho ou estudo (6.2), mostrando que continuaram fazendo planos após a maternidade, indo ao encontro do que também foi observado por Andrade et al. (2006). A gravidez, portanto, não impediu a busca de realizações. Mas, como observou-se em relação aos estudos, as adaptações foram processadas mais facilmente na presença de apoio familiar, como já foi apontado por Esteves e Menandro (2005). As dificuldades ou a ausência de planos (6.3) também foram citadas por uma adolescente que, grávida do segundo filho, mencionou que precisaria interromper novamente seus planos, dificultando a aceitação do novo bebê.

Os planos de vida, de um modo geral, centraram-se na busca de emprego, retorno às atividades escolares, desejo pela casa própria e empenho para que o filho tenha uma vida melhor, indo ao encontro do que encontraram Esteves e Menandro (2005), entre mulheres de baixa renda. Estes dados, pensados em conjunto com a ocorrência da própria gravidez, também possibilitaram uma reflexão mais ampla sobre a inserção destas jovens numa sociedade que lhes solicita o adiamento do desejo do casamento e da maternidade, em prol da continuidade do processo educacional (Coutinho, 2005). Assim, se no momento da gravidez estas adolescentes pareceram romper com as expectativas sociais de que estudassem e adiassem a maternidade, percebeu-se que, após o nascimento do filho, desenvolveram uma percepção sobre a importância desse período de preparação, passando a valorizar e sempre que possível a retomar aos estudos em busca de maior qualificação, visando melhor inserção no mercado de trabalho, evidenciando a influência do contexto em suas vidas.

\section{Considerações}

O presente estudo com mães adolescentes, numa perspectiva que considerou suas vivências desde o momento anterior à gravidez até o filho ter no mínimo um ano de idade possibilitou verificar que estas passaram por diversas transformações, que envolveram aspectos tanto subjetivos, como relacionais. Nesse sentido, e respondendo ao objetivo deste artigo, destacam-se dentre as principais, uma maior responsabilização por sua vida reprodutiva, a importância do parceiro e da mãe como fontes de suporte emocional, a reformulação de projetos de vida, a valorização dos estudos associada a dificuldades para retomálos e a satisfação com a maternidade.

Por sua vez, os resultados apresentados, que mostraram adolescentes vivendo em união estável com seus parceiros e responsabilizando-se pelos cuidados com o filho, poderiam levar à rápida conclusão de que a maior parte das entrevistadas deste estudo não encontra-se num contexto de vulnerabilidade social, especialmente quando as questões de renda e condições de vida também são consideradas e comparadas com a situação de extrema pobreza e contexto violento, no qual se desenvolvem-se alguns adolescentes. No entanto, quando se resgata o conceito de vulnerabilidade social na perspectiva de Ayres et al. (2003), identifica-se a presença de componentes que tomados em seu conjunto evidenciaram um contexto que favoreceu a gravidez entre estas jovens mulheres.

Assim, considera-se que as participantes deste estudo apresentaram características bastante singulares, com a gravidez tendo ocorrido num contexto de vulnerabilidade social, onde, no entanto, predominaram relacionamentos de afeto, tanto entre as adolescentes e seus parceiros, como em relação ao contexto familiar, sendo que a violência assumiu um papel secundário neste todo. Este aspecto divergiu do que apontou a literatura sobre a gravidez entre adolescentes nesta idade, mas ressalta-se a importância de não generalizar os resultados aqui apresentados, que poderiam ter sido diferentes se a pesquisadora tivesse como contexto de pesquisa serviços de atendimento a vítimas de violência, hospitais ou delegacias. No entanto, a singularidade dos resultados encontrados possibilita uma contribuição significativa ao campo de estudo, na medida em que evidencia processos satisfatórios de adaptação à gravidez enquanto possibilidades reais, mesmo entre mulheres tão jovens.

Assim, os limites deste estudo, demarcados a partir da fala das adolescentes, onde parceiros, familiares, profissionais e instituições estiveram representados em suas falas, sem que, no entanto, seus pontos de vista fossem contemplados, também abrem perspectivas de novas pesquisas a partir das quais o conhecimento sobre a gravidez entre adolescentes na faixa etária dos 12 aos 14 anos possa ser aprofundado. Tendo presente ainda a lacuna evidenciada entre a qualidade das diretrizes legais e de Políticas Públicas no Brasil, em contraste com a escassa menção da participação destas no discurso das adolescentes, prin- 
cipalmente no que se refere aos aspectos preventivos, ressalta-se a necessidade de estudos que avaliem a qualidade e as estratégias utilizadas pelos profissionais, que trabalham com os adolescentes, revelando como tais diretrizes vêm sendo apropriadas e aplicadas por estes.

\section{Referências}

Andrade, P. R., Ribeiro, C. A., \& Silva, C. V. (2006). Mãe adolescente vivenciando o cuidado com o filho: Um modelo teórico. Revista Brasileira de Enfermagem, 59(1), 30-35.

Ayres, J. R. C. M., França, I., Jr., Calazans, G. J., \& Saletti Filho, H. C. (2003). O conceito de vulnerabilidade e as práticas de saúde: Novas perspectivas e desafios. In D. Czeresnia (Ed.), Promoção da saúde: Conceitos, reflexões, tendência (pp. 117-139). Rio de Janeiro, RJ: Fundação Oswaldo Cruz.

Brandão, E. R., \& Heilborn, M. L. (2006). Sexualidade e gravidez na adolescência entre jovens de camadas médias do Rio de Janeiro, Brasil. Cadernos de Saúde Pública, 22(7), 1421-1430.

Caputo, V. G., \& Bordin, I. A. (2007). Problemas de saúde mental entre jovens grávidas e não-grávidas. Revista de Saúde Pública, 41(4), 573-581.

Cavasin, S., Unbehaum, S., Silva, V. N., Franco, M. H., Melo, H., Simonetti, J. R., et al. (2004). Gravidez de adolescentes entre 10 a 14 anos e vulnerabilidade social: Estudo exploratório em cinco capitais brasileiras. Rio de Janeiro, RJ: Ecos.

Cerqueira-Santos, E., Paludo, S., Schirò, E. D. B., \& Koller, S. H. (2010). Gravidez na adolescência: Análise contextual de risco e proteção. Psicologia em Estudo, 15(1), 73-85.

Cerveny, M. O. C. (2002). Visitando a família ao longo do ciclo vital. São Paulo, SP: Casa do Psicólogo.

Coutinho, L. G. (2005). A adolescência na contemporaneidade: Ideal cultural ou sintoma social. Pulsional Revista de Psicanálise, 181, 13-19.

Dias, A. C. G., \& Teixeira, M. A. P. (2010). Gravidez na adolescência: Um olhar sobre um fenômeno complexo. Paidéia, 20(45), 123-131.

Erikson, E. H. (1976). Identidade, juventude e crise (2. ed.) Rio de Janeiro, RJ: Zahar.

Esteves, J. R., \& Menandro, P. R. M. (2005). Trajetórias de vida: Repercussões da maternidade adolescente na biografia de mulheres que viveram tal experiência. Estudos de Psicologia (Natal), 10(3), 363-370.

Falcão, D. V. S., \& Salomão, N. M. R. (2006). Mães adolescentes de baixa renda: Um estudo sobre as relações familiares. Arquivos Brasileiros de Psicologia, 58(2), 11-23.

Flick, U. (2009). Introdução à pesquisa qualitativa (3. ed.). Porto Alegre, RS: Artmed.

Godinho, R. A., Schelp, J. R. B., Parada, C. M. G. L., \& Bertoncello, N. M. F. (2000). Adolescentes e grávidas: Onde buscam apoio? Revista Latino-americana de Enfermagem, $8(2), 25-32$.

Gradim, C. V. C., Ferreira, M. B. L., \& Moraes, M. J. (2010). O perfil das grávidas adolescentes em uma unidade de saúde da família de Minas Gerais. Revista de Atenção Primária à Saúde, 13(1), 55-61.

Heilborn, M. L., Salen, T., Rohden, F., Brandão, E., Knauth, C. V., Aquino, E., et al. (2002). Aproximações socioantropológicas sobre a gravidez na adolescência. Horizontes Antropológicos, 8(17), 13-45.
Hoga, L. A. K. (2008). Adolescent maternity in a low income community: Experiences revealed by oral history. Revista Latino-americana de Enfermagem, 16(2), 280-286.

Hoga, L. A. K., Borges, A. L. V., \& Heberte, L. M. (2010). Razões e reflexos da gravidez na adolescência: Narrativas dos membros da família. Escola Anna Nery Revista de Enfermagem, 14(1), 151-57.

Instituto Brasileiro de Geografia e Estatística. (2000). Censo demográfico. Rio de Janeiro, RJ: Autor.

Levandowski, D. C., Piccinini, C. A., \& Lopes, R. C. S. (2008). Maternidade adolescente. Estudos de Psicologia (Campinas), 25(2), 251-263

López, L. S., Alvarez, M. A., Yáñez, P. R., Aranis, L. R., Yovane, C., Rugama, A. O., et al. (2005). Autoconcepto y proyecto de vida: percepciones de adolescentes embarazadas de un sector periférico de Santiago, participantes de un programa de educación para la salud. Revista de Psicologia Universidad de Chile, 14(1), 141-152.

Ministério da Saúde. (2006). Indicadores de morbidade e fatores de risco. Sistema de informações sobre nascidos vivos. Proporção de nascidos vivos por idade materna. Brasília, DF: Autor

Miño-Worobiej, A. (2008). Imágenes de género y conductas sexual y reproductiva. Salud Publica de México, 50, 17-31.

Morin, E. (2005). Introdução ao pensamento complexo. Porto Alegre, RS: Sulina.

Organização Mundial da Saúde. (1965). Problemas de la salud de la adolescencia. Informe de un comité de expertos de la O.M.S (Informe técnico $\mathrm{n}^{\circ}$ 308). Ginebra, Suíça: Autor.

Rugolo, L. M. S. S., Bottino, J., Scudeler, S. R. M., Bentlin, M. R., Trindade, C. E. P., Perosa, G. B., et al (2004). Sentimentos e percepções de puérperas com relação à assistência prestada pelo serviço materno-infantil de um hospital universitário. Revista Brasileira de Saúde Materno Infantil, 4(4), 423-433.

Sabroza, A. R., Leal, M. C., Souza, P. R., Jr., \& Gama, S. G. N. (2004). Algumas repercussões emocionais negativas da gravidez precoce em adolescentes do Município do Rio de Janeiro (1999-2001). Cadernos de Saúde Pública, 20(1), 130-137.

Sluzki, C. E. (1997). A rede social na prática sistêmica (C. Berliner, Trad.). São Paulo, SP: Casa do Psicólogo

Souza-Mata, A. N., Araújo-Lemos, C., Lira-Ferreira, C., Pereira-Braga, L., \& Chaves-Maia, E. M. (2009). Fatores de risco na repetição de gravidez na adolescência. Revista Colombiana de Psicologia, 18(2), 167-175.

Strauss, A., \& Corbin, J. (2008). Pesquisa qualitativa: Técnicas e procedimentos para o desenvolvimento de teoria fundamentada (L. O. Rocha, Trad.). Porto Alegre, RS: Artmed

Taquette, S. R. (2008). Sobre a gravidez na adolescência. Adolescência \& Saúde, 5(2), 23-26.

Velho, M. T. A. C. (2003). Gestação na adolescência: Um marco na construção do ser-mulher. (Tese de Doutorado nãopublicada). Universidade Federal de Santa Catarina, Florianópolis, SC. 